\title{
Display of $E$. coli Alkaline Phosphatase pIII or pVIII Fusions on Phagemid Surfaces Reveals Monovalent Decoration with Active Molecules
}

\author{
Michael Weichel ${ }^{1}$, Rolf Jaussi ${ }^{2}$ Claudio Rhyner ${ }^{1}$ and Reto Crameri*, ${ }^{*}$ \\ ${ }^{I}$ Swiss Institute of Allergy and Asthma Research (SIAF), Obere Strasse 22, CH-7270 Davos, Switzerland; ${ }^{2}$ Biomolecular \\ Research, Paul Scherrer Institut, CH-5232 Villigen PSI, Switzerland
}

\begin{abstract}
Active alkaline phosphatase of Escherichia coli (PhoA, EC 3.1.3.1) was displayed via the leucine zipper element of the Jun-Fos heterodimer on the surface of filamentous phage and the kinetic parameters $K_{\mathrm{m}}$ and $k_{\text {cat }}$ were determined. The $p h o A$ gene was cloned downstream of fos while jun was inserted upstream of $p I I I$ or $p V I I I$, alternatively, in the pJuFo phagemid vector. Both fusion genes are regulated by independent lacZ promoters. PhoA displayed on the phagemid pIII surface exhibited a $K_{\mathrm{m}}$ of $11.2 \mu \mathrm{M}$ with 4-nitrophenyl phosphate as substrate, which is consistent with data published for soluble PhoA. Based on these data we calculated the decoration of pJuFo phagemid with PhoA using the minor and major coat proteins $\mathrm{pIII}$ and $\mathrm{pVIII}$ as fusion partners under variable inducing conditions. We found that, even if the promoters are fully induced at a concentration of $1000 \mu \mathrm{M}$ IPTG, the phagemids display maximally one copy of PhoA-FosJun-coat protein fusion, irrespective of whether the protein is presented via pIII or pVIII. However, since PhoA is displayed in a native-like fashion, as deduced from the kinetic parameters of the enzymatic reaction, the pJuFo technology provides a versatile tool for the functional screening of complex cDNA libraries displayed on the phagemids' surface.
\end{abstract}

\section{INTRODUCTION}

Most functional proteomic approaches aim at the identification of interactions between naturally occurring proteins. Once the interactions are known the resulting interactome networks can provide information about complex molecular interactions and improve our understanding of evolutionary, metabolic, molecular and cellular processes [1]. Recently, enhanced modifications of the original yeast two-hybrid system [2] have been used to generate entire interaction maps of the yeast Saccharomyces cerevisiae [3,4] and the nematode worm Caenorhabditis elegans [5]. The problem of relatively frequent false-positive hints remains a major disadvantage of this in vivo technology [6]. As an alternative, lambda phage based screening or phage surface display of cDNA libraries are often favoured over the two-hybrid system, if a library needs to be screened against an immobilized monoclonal or oligoclonal ligand because both in vitro screening systems allow variation of the binding conditions.

Phage display differs from other screening systems because molecular libraries incorporated into the phage genome are expressed on the surface of phage particles [7]. The physical linkage between genotype and phenotype allows maintaining a phage library in the liquid phase and therefore efficient screening based on the power of affinity selection. cDNA phage display systems based on bacteriophages T7 [8, 9], lambda [10], and filamentous phage [11-15] have been recently reported and reviewed elsewhere [16, 17].

Among the filamentous phage display approaches the pJuFo technology, which is based on an indirect fusion approach to display products on the surface of helper phage

*Address correspondence to these authors at the Swiss Institute of Allergy and Asthma Research (SIAF), Obere Strasse 22, CH-7270 Davos, Switzerland; E-mail: crameri@siaf.uzh.ch assisted phagemid assemblies, has widely been used for the surface expression of cDNA libraries, and yielded complex allergen repertoires of various allergenic sources [18]. Furthermore, the technology provided a valuable tool for the identification of tumor-associated antigens [19], selfantigens [20] or epitopes of polyclonal antibody sera [21]. Since the applications of this methodology are quite diverse, and yet it has not met substantial limitations, we investigated the efficiency of the pJuFo surface presentation choosing $E$. coli alkaline phosphatase (PhoA, EC 3.1.3.1) as a model system. PhoA was cloned adjacent to fos of the pJuFo vector and expressed as a Jun-Fos-pIII or Jun-Fos-pVIII fusion protein on the phagemids' surface (Fig. 1). Under reaction conditions in which PhoA exhibits Michaelis-Menten behaviour we obtained the kinetic parameters $K_{\mathrm{m}}$ and $k_{\text {cat }}$ of phagemiddisplayed PhoA. Comparison of these kinetic parameters with those of wild-type PhoA allowed calculating the decoration of phagemid with functional PhoA fusion proteins.

\section{MATERIALS AND METHODS}

\section{Construction of pJuFoVIII::phoA}

Production of phage displaying PhoA of E. coli as a pIII fusion protein by means of the Jun-Fos linker is described elsewhere $[11,37]$. For the construction of a pVIII-display pJuFo vector, the DNA encoding pVIII was amplified by PCR using M13K07 helper phage as a template and the following oligonucleotides: 5'-primer pVIII: 5'-ACG GGA TCC GGT GGC GGT GGC TCT GCT GAG GGT GAC-3', 3'-primer pVIII: 5'-GTG TTA CTA GCT AGC TTT AAT TGT ATC GGT TTA-3'. The PCR fragment was hydrolysed with BamHI and NheI, gel purified and used to replace the BamHI-NheI fragment in pJuFo. The ligation mixture was used to transform E. coli XL1-Blue (Stratagene, La Jolla, CA, USA) electrocompetent cells [38] which were then spread on LB agar plates with $100 \mu \mathrm{g} / \mathrm{ml}$ ampicillin and 10 


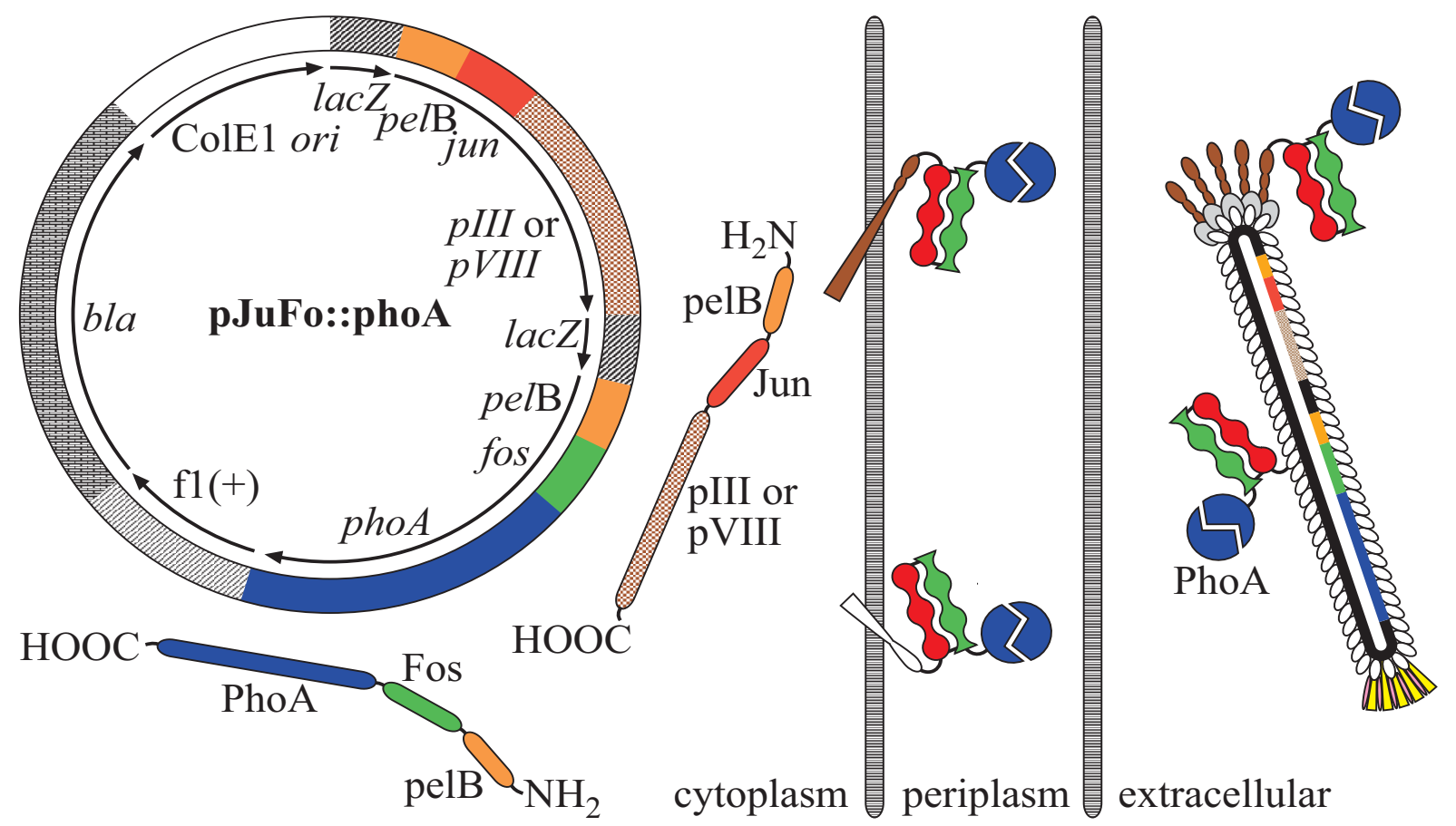

Fig. (1). Genetic elements of the pJuFo vector and proposed mechanism for the assembly of PhoA-phagemids. In the present work PhoA was displayed either as pIII or pVIII fusion protein via the heterodimeric Jun-Fos linker on the surface of filamentous phagemid.

$\mu \mathrm{g} / \mathrm{ml}$ tetracycline (LB/Amp+Tc). Single colonies were picked and grown. DNA was prepared and the final construct was was verified by restriction analysis and DNA sequencing (Microsynth, Balgach, Switzerland). The pJuFoVIII:: phoA phagemid was constructed by $X b a \mathrm{I}+K p n \mathrm{I}$ hydrolysis of the pJuFoVIII vector and ligation with correspondingly hydrolysed phoA DNA derived from pJuFoIII::phoA [11].

\section{Preparation of PhoA-Phagemids}

$110-150 \mathrm{ml} 2 \times \mathrm{YT}$ medium with $100 \mu \mathrm{g} / \mathrm{ml}$ ampicillin and $10 \mu \mathrm{g} / \mathrm{ml}$ tetracycline $(2 \times \mathrm{YT} / \mathrm{Amp}+\mathrm{Tc})$ were inoculated 1:50 with a stationary culture of $E$. coli XL1Blue/pJuFo::phoA or XL1-Blue/pJuFoVIII::phoA and incubated at $37^{\circ} \mathrm{C}$ and $250 \mathrm{rpm}$ until an $\mathrm{OD}_{550}$ of $\approx 0.5$ was reached. Then helper phage VCS-M13 (Stratagene) was added at a multiplicity of infection (moi) of 10 and the culture was incubated for $30 \mathrm{~min}$ at $30^{\circ} \mathrm{C}, 150 \mathrm{rpm}$. After 30 min agitation of the culture was raised to $300 \mathrm{rpm}$ and the culture was incubated for additional $9.5 \mathrm{~h}$ at $30^{\circ} \mathrm{C} .2 \mathrm{~h}$ after infection with helper phage, kanamycin (kan) was added to a concentration of $70 \mu \mathrm{g} / \mathrm{ml}$. For experiments, in which the decoration of phage with PhoA was determined in dependence of the inducer concentration, IPTG was added $30 \mathrm{~min}$ after infection with helper phage.

PhoA-phagemid containing supernatant was prepared 10 $\mathrm{h}$ after helper phage addition by centrifugation $(4 ' 500 \times g$, $4^{\circ} \mathrm{C}, 15 \mathrm{~min}$ ) and PhoA-phagemid was precipitated by addition of $1 / 4$ volume $25 \%(\mathrm{w} / \mathrm{v})$ polyethylene glycol $(\mathrm{MW}$ : 8 (000), $15 \%(\mathrm{w} / \mathrm{v}) \mathrm{NaCl}$ at $4^{\circ} \mathrm{C}$ for $20 \mathrm{~min}$. After centrifugation $\left(15^{\prime} 000 \times g, 4^{\circ} \mathrm{C}, 20 \mathrm{~min}\right)$ the supernatant was removed and the precipitated phagemid was dissolved in $10 \mathrm{mM}$ Tris/ $\mathrm{HCl}$ pH 8.0 (4 vol. \% of the original supernatant volume). After centrifugation $\left(15^{\prime} 000 \times g, 4^{\circ} \mathrm{C}, 10 \mathrm{~min}\right)$ the cleared solution was transferred into fresh tubes and PhoAphagemid was precipitated again with $\mathrm{PEG} / \mathrm{NaCl}$ as de- scribed above, the supernatant was removed quantitatively and precipitated PhoA-phagemid was dissolved in $10 \mathrm{mM}$ Tris/HCl pH 8.0 (4 vol. \% of the original supernatant volume). After final centrifugation $\left(15^{\prime} 000 \times g, 4^{\circ} \mathrm{C}, 10 \mathrm{~min}\right)$ the PhoA-phagemid solution was transferred into new tubes, kept at $4^{\circ} \mathrm{C}$ and readily used for the determination of infectivity and for enzymatic assays. Samples immediately not used for experiments were stored at $-20^{\circ} \mathrm{C}$ directly after preparation.

\section{Inducibility of pJuFoIII::phoA and pJuFoVIII::phoA}

To test the inducibility of the phagemid vectors by IPTG after addition of helper phage we prepared periplasmic extracts of XL1-Blue using a moderately modified protocol for cold osmotic shock [39]: portions of $25 \mathrm{ml}$ were taken from a $200 \mathrm{ml}$ PhoA-phagemid producing XL1-Blue culture at distinct times after VCS-M13 superinfection and centrifuged $\left(4^{\prime} 500 \times \mathrm{g}, 4^{\circ} \mathrm{C}, 15 \mathrm{~min}\right)$. The supernatant was removed completely and bacterial pellets washed by gentle resuspension in $1 \mathrm{ml}$ of $2 \times \mathrm{YT}$ followed by centrifugation $\left(4500 \times \mathrm{g}, 4^{\circ} \mathrm{C}, 15 \mathrm{~min}\right)$. After medium removal the bacteria were resuspended in $1 \mathrm{ml} 500 \mathrm{mM}$ Saccharose, $100 \mathrm{mM}$ Tris/HCl, $1 \mathrm{mM}$ EDTA pH 8.0 and incubated on ice for 30 min in the presence of $100 \mu \mathrm{g} / \mathrm{ml}$ hen egg white lysozyme (Roche, Basel, Switzerland). The spheroplasts were sedimented $\left(15^{\prime} 000 \times \mathrm{g}, 4^{\circ} \mathrm{C}, 15 \mathrm{~min}\right)$ and the periplasmic fractions were stored at $-20^{\circ} \mathrm{C}$.

\section{Western Blots}

Western blot analysis was used to detect wild-type (wt) PhoA (Sigma, St. Louis, MO, USA) or Fos-PhoA in the periplasmic fractions as well as in the phagemid preparations. Therefore, samples were subjected to SDS-PAGE (NuPAGE $^{\mathrm{TM}}, 12 \%$ Bis-Tris, Invitrogen $^{\mathrm{TM}}$ ) and electrotransferred onto a Hybond ${ }^{\mathrm{TM}}-\mathrm{P}$ PVDF membrane (Amersham Pharmacia 
Biotech, Uppsala, Sweden). Free binding sites were blocked with 5\% non-fat dried milk, $0.1 \%$ (v/v) Tween-20 in TBS. PhoA was detected with horse radish peroxidase labelled rabbit polyclonal anti-bacterial AP mAb 7319 (1:10'000 in blocking buffer, Abcam, Cambridge, United Kingdom) and visualised by chemiluminescence (ECL ${ }^{\mathrm{TM}}$, Amersham Pharmacia Biotech) substrate.

\section{Enzymatic Assays}

PhoA-phagemid enzyme activity was assayed basically as described by McCafferty et al. [31]. Briefly, reactions were initiated by adding $50 \mu \mathrm{l}$ PhoA-phagemid solution to $950 \mu \mathrm{l}$ of 4-nitrophenyl phosphate (Fluka, Buchs, Switzerland) at a range of concentrations in $1.052 \mathrm{M}$ Tris/ $\mathrm{HCl} \mathrm{pH}$ 8.0. The initial rates were calculated from the change of the absorbance at $410 \mathrm{~nm}$ in the first $6 \mathrm{~s}$ of each reaction at $25^{\circ} \mathrm{C}$ using a molar absorption coefficient of $16^{\prime} 200 \mathrm{M}^{-1} \mathrm{~cm}^{-1}$ [40]. The concentration of PhoA-phagemid was determined by preparing ssDNA using phenol/chloroform/ isopropanol extraction, ethanol precipitation and measuring at $260 \mathrm{~nm}$. The $\mathrm{A}_{260} / \mathrm{A}_{280}$ ratio of the ssDNA prepared this way was always higher than 1.77. The molar absorption coefficients of the individual single stranded vector contructs were calculated with the Omiga 2.0 software (Oxford Molecular, Oxford, England). Purified E. coli PhoA was purchased from Sigma. The concentration was calculated by measuring the absorbance at $278 \mathrm{~nm}$ [41] using a $M_{\mathrm{r}}$ of $47^{\prime} 029$ per subunit [28]. The kinetic parameters $K_{\mathrm{m}}$ and $k_{\text {cat }}$ were derived fromnonlinear least-square fits according to the Michaelis-Menten model. For practical reasons $k_{\text {cat }}$ values are expressed as molar activities (mol. act.) and specified in mol substrate/mol phage (or enzyme)/min throughout this paper. All absorption measurements were performed on an Uvikon XL spectrophotometer (Bio-Tek Instruments, Winooski, VT, USA).

\section{Phagemid Infectivity}

Infectivity is defined as the ratio between infective and total phage. Total phagemid was measured by preparing ssDNA as described above, infective phagemid was determined by infecting exponentially growing E. coli XL1-Blue with three independent dilution series of each phagemid preparation and plating out on LB/Amp+Tc agar.

\section{RESULTS}

\section{Kinetic Properties of PhoA Displayed on the Surface of pJuFo Phagemids}

Display of cDNA libraries on the surface of filamentous phage and their screening for interacting proteins against immobilized targets still remains a challenge in proteomics. Although also $\mathrm{pVI}$ as fusion partner for cDNA products has been described [13, 14, 22], the pJuFo technology which uses the pIII-Jun-Fos-cDNA fusion is well established for the efficient selection and identification of protein-protein interacting partners [16]. To determine if these proteins are displayed in a native-like conformation, we have generated phagemid vectors displaying $E$. coli PhoA on the surface of filamentous phage particles as pIII or pVIII fusion proteins via the Jun-Fos linker, determined the kinetic parameters of the phagemid-displayed enzymes and compared them to those of soluble PhoA. It has been shown previously that functional PhoA can be displayed on the surface of filamentous phage $[11,14,15,23]$. However, only McCafferty et al.
[23] provide detailed kinetic data and show that PhoA directly fused to the $\mathrm{N}$-terminus of pIII exhibits a different $K_{\mathrm{m}}$ compared to soluble PhoA.

As shown in Table 1 PhoA displayed on pJuFo - III phagemids exhibits a $K_{\mathrm{m}}$ of $11.2 \mu \mathrm{M}$, which is in agreement with published data of soluble PhoA [23, 24]. This value is independent from PhoA being displayed as pIII or pVIII fusion and independent of the IPTG concentration under which the nascent PhoA-phagemid is being produced.

Table 1. Michaelis Constants of Different Phagemid Preparations and of Soluble PhoA

\begin{tabular}{|c|c|c|}
\hline Sample & $\mathbf{c}($ IPTG) $[\mu \mathrm{M}]$ & $K_{\mathrm{m}}[\mu \mathrm{M}]^{\mathrm{d})}$ \\
\hline pIII-PhoA & 0 & $11.2( \pm 0.1)$ \\
\hline pIII-PhoA & 1 & $12.3( \pm 0.9)$ \\
\hline pIII-PhoA & 10 & $9.0( \pm 0.8)$ \\
\hline pIII-PhoA & 100 & $9.8( \pm 1.1)$ \\
\hline pIII-PhoA & 1000 & $10.1( \pm 1.2)$ \\
\hline pVIII-PhoA & 0 & $12.9( \pm 1.0)$ \\
\hline pVIII-PhoA & 1 & $12.9( \pm 1.2)$ \\
\hline pVIII-PhoA & 10 & $12.3( \pm 0.9)$ \\
\hline pVIII-PhoA & 100 & $11.0( \pm 0.7)$ \\
\hline pVIII-PhoA & 1000 & $11.0( \pm 0.6)$ \\
\hline $\mathrm{PhoA}^{\text {a) }}$ & & $12.3( \pm 0.2)$ \\
\hline $\mathrm{PhoA}^{\mathrm{b})}$ & & 12.7 \\
\hline $\mathrm{PhoA}^{\mathrm{c})}$ & & 8.5 \\
\hline
\end{tabular}

${ }^{\text {a) }} \mathrm{Km}$ from the present work, ${ }^{\text {b) }} K_{\mathrm{m}}$ from [24], ${ }^{\mathrm{c})} K_{\mathrm{m}}$ from [23]. ${ }^{\mathrm{d})}$ The standard deviation derived from three experiments performed with independent freshly prepared phagemids is given in parentheses.

Assuming that the individual rate constants composing $K_{\mathrm{m}}$ of PhoA-phagemid are comparable to those of soluble PhoA the number of active enzyme molecules displayed on each phagemid particle can be calculated. Fig. (2) shows the molar activities of wtPhoA, PhoA-pIII-phagemid and PhoApVIII-phagemid produced in the absence of IPTG. Under this condition PhoA is presented nearly twice as effectively via pIII than via pVIII. However, PhoA-pIII-phagemid shows a molar activity of $1587 \mathrm{~mol}$ substrate/mol phage $/ \mathrm{min}$ compared to a molar activity of $3539 \mathrm{~mol}$ substrate $/ \mathrm{mol}$ enzyme/min for soluble PhoA, indicating that only $45 \%$ of the phagemids display one active enzyme molecule via pIII.

Another aim of this study was to investigate if and to what extend addition of IPTG during phagemid production would increase the decoration of phagemids with active enzyme. We therefore tested in a first step the inducibility of the pJuFo::phoA vectors by preparing periplasmic fractions from phagemid producing XL1-Blue cultures grown with or without $1 \mathrm{mM}$ IPTG. The periplasmic fractions were then subjected to Western blot analysis and the Fos-PhoA fusion protein was detected by HRP-labelled anti-bacterial PhoA $\mathrm{mAb}$ 7319. As shown in Fig. (3), induction of fos::phoA expression is enhanced with IPTG in either of the phagemid vectors during the entire period of phage propagation. Surprisingly, the difference in fos::phoA expression with and without IPTG is much less pronounced in pJuFoIII::phoA (Fig. 3A) compared to pJuFoVIII::phoA (Fig. 3B). This difference might be more obvious if we consider that the perip- 
lasmic extracts of the cultures grown in medium with $1 \mathrm{mM}$ IPTG were prepared from a 10 to $15 \%$ reduced cell number compared to those grown without IPTG (Fig. 3C).

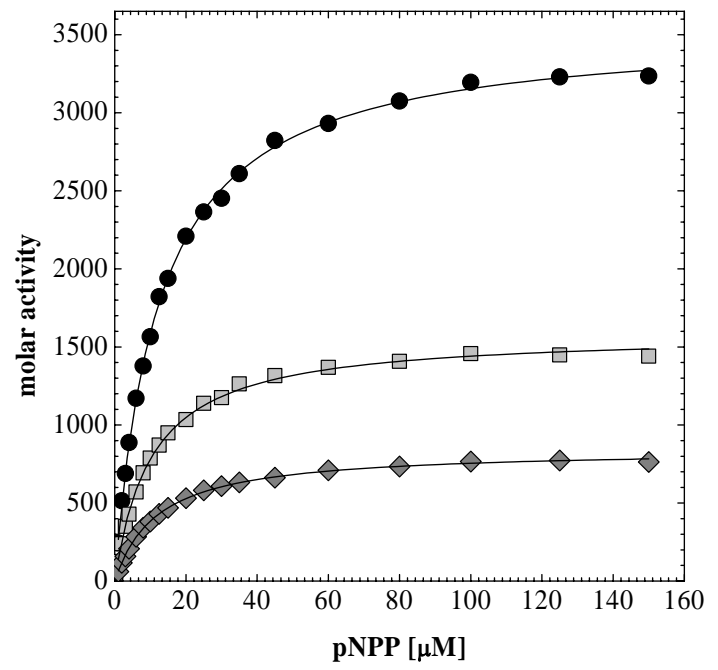

Fig. (2). Michaelis-Menten plot of soluble PhoA (solid black circles), PhoA-pIII-phagemid (light grey squares) and PhoA-pVIIIphagemid (dark grey diamonds). Molar activities are plotted against the substrate concentration to calculate the kinetic parameters summarized in Table $\mathbf{1}$.

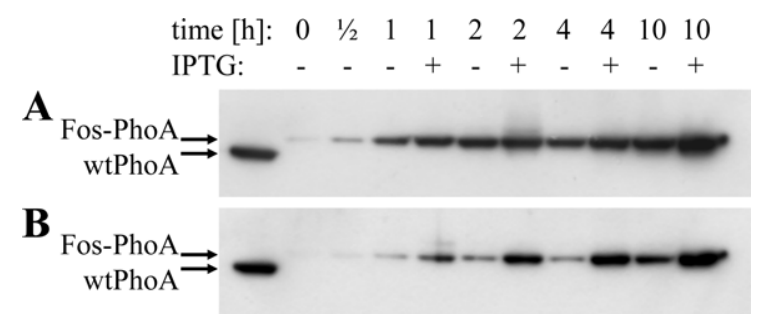

C

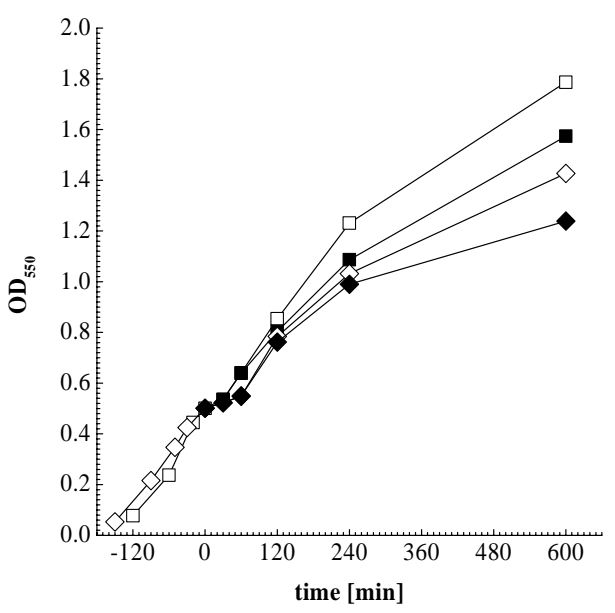

Fig. (3). Western blot analysis of periplasmic extracts directly before, $1 / 2 \mathrm{~h}, 1 \mathrm{~h}, 2 \mathrm{~h}, 4 \mathrm{~h}$ and $10 \mathrm{~h}$ after helper phage superinfection, and of soluble wtPhoA (left lane). (A) Fos-PhoA detected in XL1Blue harbouring pJuFoIII::phoA without (-) and in the presence of $1 \mathrm{mM}$ IPTG (+). (B) Fos-PhoA detected in XL1-Blue harbouring pJuFoVIII::phoA grown without (-) and in the presence of $1 \mathrm{mM}$ IPTG (+). (C) Growth rate of XL1-blue/pJuFoIII::phoA (squares) and XL1-blue/pJuFoVIII::phoA (circles) grown without (open symbols) and with $1 \mathrm{mM} \mathrm{IPTG} \mathrm{(solid} \mathrm{symbols).}$
To directly investigate the effect of the inducer on the valency of PhoA-phagemids we then added IPTG to final concentrations of $1 \mu \mathrm{M}, 10 \mu \mathrm{M}, 100 \mu \mathrm{M}$ and $1000 \mu \mathrm{M} 30$ min after $10 \mu \mathrm{M}, 100 \mu \mathrm{M}$ and $1000 \mu \mathrm{M} 30$ min after infecting the bacteria with helper phage and prepared the phagemids after another $9 \frac{1}{2} \mathrm{~h}$. The molar activities of these PhoA-phagemids are shown in Fig. (4). We observed a twofold increase of PhoA-pVIII-phagemid activity in the range between $1 \mu \mathrm{M}$ and $10 \mu \mathrm{M}$ IPTG with an apparent activity saturation at IPTG concentrations higher than $10 \mu \mathrm{M}$. An increase in molar activity could also be detected in the case of PhoA-pIII-phagemids at IPTG concentrations $\geq 10 \mu \mathrm{M}$, but it was much less pronounced. Because both jun::gIII and fos::phoA are under control of lacZ promotors, we consider this behaviour to reflect the in vivo dissociation constant of inducer and Lac repressor, which is $5.7 \mu \mathrm{M}$ [25].

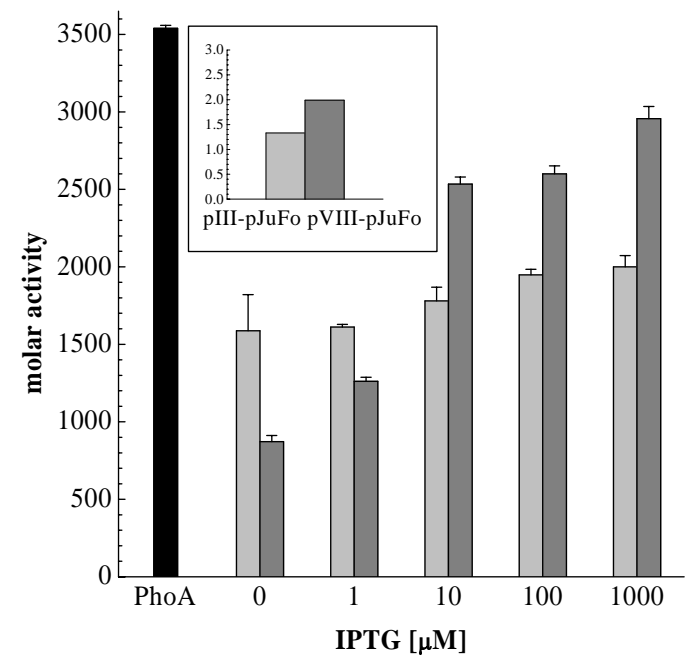

Fig. (4). Molar activities of soluble dimeric PhoA (black), PhoApIII-phagemid (light grey) and PhoA-pVIII-phagemid (dark grey) in dependence on the IPTG concentration. Molar activities of PhoA-phagemid are measured per phage particle. As control pIIIpJuFo and pVIII-pJuFo phagemids without a PhoA fusion were used. The molar activities of these control samples were 1.33 and $1.99 \mathrm{~mol}$ substrate converted/mol phage/min respectively (small figure top left).

The finding that a maximum of one copy of PhoA is displayed on either species of pJuFo phagemids could also be confirmed by Western blot analysis (Fig. 5).

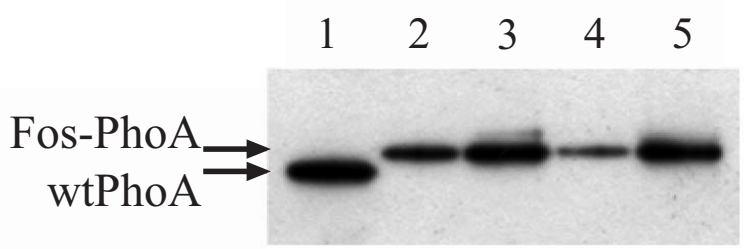

Fig. (5). Western blot analysis of $10^{112}$ phage particles (quantified by $A_{260}$ measurements) prepared $10 \mathrm{~h}$ after helper phage infection and detection by polyclonal anti-PhoA rabbit antibody ab7319. Lane 1: $7.81 \cdot 10^{-5} \mathrm{mg}$ wtPhoA (= $10^{12} \mathrm{PhoA}$ subunits). Lane 2: PhoA-pIII-phagemid amplified without IPTG. Lane 3: PhoA-pIIIphagemid amplified in the presence of $1 \mathrm{mM}$ IPTG. Lane 4: PhoApVIII-phagemid amplified without IPTG. Lane 3: PhoA-pVIIIphagemid amplified in the presence of $1 \mathrm{mM}$ IPTG. 
However, it should be annotated that both total phagemid yield as well as their infectivity decrease with increasing IPTG concentration as shown in Fig. (6).

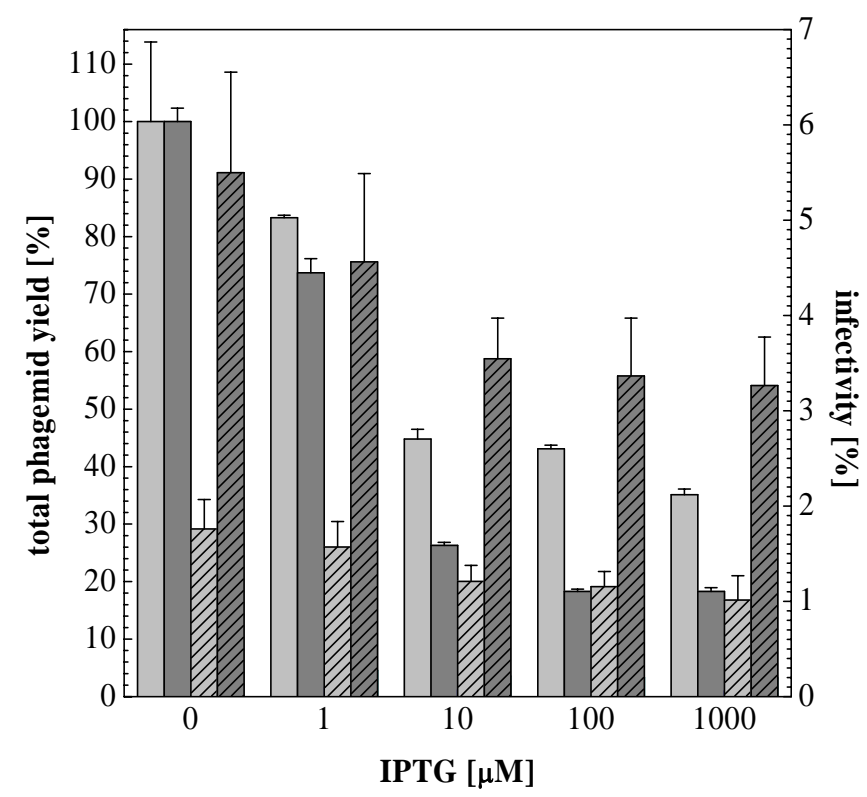

Fig. (6). Phage yields (solid bars), and infectivities (diagonals) of PhoA-pIII-phagemid (light grey) and PhoA-pVIII-phagemid (dark grey) preparations in the absence and presence of IPTG during phage production. $100 \%$ represent $4 \cdot 10^{13}$ phagemids/ml (PhoApIII-phagemid) and $9 \cdot 10^{13}$ phagemids/ml (PhoA-pIII-phagemid) respectively. Infectivity is measured in transforming units per $\mathrm{ml}$.

The titer of PhoA-pIII-phagemids produced at IPTG concentrations $\geq 10 \mu \mathrm{M}$ was less than $50 \%$ compared to the phagemid titers obtained without induction, while infectivity decreased almost twofold from 1.8 to 1.0 percent. For PhoApVIII-phagemids the total yield even dropped below $30 \%$ at IPTG concentrations $\geq 10 \mu \mathrm{M}$, while infectivity decreased from 5.5 (no IPTG) to 3.3 percent (1000 $\mu \mathrm{M}$ IPTG) and thus was always higher compared to the pIII fusion. However, infectivity of PhoA-pVIII-phagemids decreased significantly after $48 \mathrm{~h}$ storage at $4^{\circ} \mathrm{C}$, indicating that the phage displaying the PhoA-pVIII fusion protein is less stable than the phage displaying the PhoA-pIII fusion protein (data not shown). Therefore we recommend the use of pIII as a fusion partner for phage surface display of cDNA libraries.

\section{DISCUSSION}

Success and failure of phage display methods critically depend on distinct experimental variables and parameters, as was indicated on the basis of stochastic models [26]. Besides the effective concentration of immobilized high affinity ligands and the stringency of washing steps, particularly complexity and titer of a phage library as well as valency of phage have an impact on the outcoming of a biopanningbased selection experiment. In order to investigate valency, infectivity and display quality of the pJuFo phagemid, which has proven a versatile vector for the screening of cDNA libraries of various allergic sources [18], human tumor cells [19], mice B cells [27], and human fibroblasts [20], we generated $\mathrm{pJuFo}$-PhoA phagemids in which PhoA was either fused to the minor coat protein pIII or to the major coat pro- tein pVIII via a Jun-Fos linker. PhoA is a homodimeric protein located in the periplasm of E. coli and has a molar mass of $47 \mathrm{kDa}$ per subunit [28]. There is strong evidence from the literature that only dimeric PhoA is catalytically active $[29,30]$. Therefore, it was surprising that the Michaelis constant $K_{\mathrm{m}}$ of the phage-displayed PhoA was identical to that of soluble PhoA (Table 1), indicating that dimeric proteins can be displayed in a native-like fashion on the surface of $\mathrm{pJuFo}$ phagemids and that the two intramolecular disulfide bonds present in the PhoA subunit are formed correctly. Furthermore, we may conclude that the individual rate constants composing $K_{\mathrm{m}}$ in the PhoA-phagemids are identical to those of soluble PhoA. Thus, $k_{\text {cat }}$ or molar activities of PhoAphagemids and soluble PhoA may be compared directly to calculate the valency of PhoA-phagemids.

As shown in Fig. (4) all of the PhoA-phagemid populations prepared from incubations with or without IPTG display lower activity than the soluble PhoA indicating that statistically maximally one of the five [31] copies of pIII and one of 2700 copies of pVIII represents a PhoA-coat protein fusion. This observation is supported by Western blot analysis (Fig. 5), and thus we may conclude that the majority of the displayed PhoA fusion molecules are also enzymatically active.

It has been shown earlier that the decoration of filamentous hybrid phage with peptides fused to pVIII critically depends on the length of the peptide [32-34] and, even more, on the rate of processing of the molar pro-coat fusion protein [35] which is a critical step in recombinant phage assembly. As a result the infectivity of phage populations that display a 10 or 16 amino acid peptide drops from $20 \%$ to $1 \%$ [34], respectively. Malik et al. [40] have impressively demonstrated by Western blot analysis that 12 mers and 16 mers can be displayed in up to $40 \%$ and $25 \%$ of the pVIII copies, respectively. According to their model-building approach the phage coat could even be decorated with a folded $100 \mathrm{kDa}$ protein at a saturation of $24 \%$ [35]. However, experiments in which the display of a scFv via pIII and pVIII was directly compared by ELISA clearly showed that pIII was more efficient than pVIII in displaying coat fusion proteins even though there are much less copies of pIII present in a phage particle [36]. Those results generally corroborate our findings that the display of PhoA via $\mathrm{pIII}$ is more efficient than via $\mathrm{pVIII}$ when the PhoA-coat protein fusion is produced from a phagemid vector in the absence of induction (Fig. 2). But so far there is no hint in the literature why the copy number of displayed PhoA should be restricted to one per phage particle, even when fused to the major coat protein pVIII.

When produced in the presence of IPTG as strong inducer of the lacZ promoter, the titer of PhoA-pVIIIphagemids was always lower compared to PhoA-pIIIphagemids. However, the infectivity of the PhoA-pVIIIphagemid remained higher than that of the PhoA-pIIIphagemid.

Taken into account that the complexity of a primary cDNA library is usually in the range of $10^{\gamma}$ primary clones and that the amplified phagemid populations from all experiments exceeded a titer of $1 \cdot 10^{11}$ transforming units per $\mathrm{ml}(\mathrm{tu} / \mathrm{ml})$ it remains irrelevant whether the cDNA products are displayed via pIII or pVIII. In any case the cDNA library 
will be entirely displayed on the phage surface and makes pJuFo an ideal phagemid vector for the screening of cDNA libraries from various origins.

\section{ACKNOWLEDGEMENTS}

We thank Dr. Patrik Forrer for providing us with the pJuFo-pVIII vector. Work supported by the Swiss National Science Foundation (grants no. 3100-63381 / 2 and 310000114634 / 1) and by the OPO-Pharma Foundation, Zürich.

\section{REFERENCES}

[1] Figeys, D. Brief. Funct. Genomic. Proteomic, 2004, 2, 357.

[2] Fields, S.; Song, O. Nature, 1989, 340, 245.

[3] Uetz, P.; Giot, L.; Cagney, G.; Mansfield, T.A.; Judson, R.S.; Knight, J.R.; Lockshon, D.; Narayan, V.; Srinivasan, M.; Pochart, P.; Qureshi-Emili, A.; Li, Y.; Godwin, B.; Conover, D.; Kalbfleisch, T.; Vijayadamodar, G.; Yang, M.; Johnston, M.; Fields, S.; Rothberg, J.M. Nature, 2000, 403, 623.

[4] Ito, T.; Chiba, T.; Ozawa, R.; Yoshida, M.; Hattori, M.; Sakaki, Y. Proc. Natl. Acad. Sci. USA, 2001, 98, 4569.

[5] Li, S.; Armstrong, C.M.; Bertin, N.; Ge, H.; Milstein, S.; Boxem, M.; Vidalain, P.O.; Han, J.D.; Chesneau, A.; Hao, T.; Goldberg, D.S.; Li, N.; Martinez, M.; Rual, J.F.; Lamesch, P.; Xu, L.; Tewari, M.; Wong, S.L.; Zhang, L.V.; Berriz, G.F.; Jacotot, L.; Vaglio, P.; Reboul, J.; Hirozane-Kishikawa, T.; Li, Q.; Gabel, H.W.; Elewa, A.; Baumgartner, B.; Rose, D.J.; Yu, H.; Bosak, S.; Sequerra, R.; Fraser, A.; Mango, S.E.; Saxton, W.M.; Strome, S.; Van Den Heuvel, S.; Piano, F.; Vandenhaute ., Sardet, C.; Gerstein, M.; Doucette-Stamm, L.; Gunsalus, K.C.; Harper, J.W.; Cusick, M.E.; Roth, F.P.; Hill, D.E.;Vidal, M. Science, 2004, 303, 540.

[6] Serebriiskii, I.; Estojak, J.; Berman, M.; Golemis, E.A. Biotechniques, 2000, 28, 328.

[7] Smith, G.P. Science, 1985, 228, 1315

[8] Danner, S.; Belasco, J.G. Proc. Natl. Acad. Sci. USA, 2001, 98, 12954.

[9] Zozulya, S.; Lioubin, M.; Hill, R.J.; Abram, C.; Gishizky, M.L. Nat. Biotechnol., 1999, 17, 1193

[10] Santi, E.; Capone, S.; Mennuni, C.; Lahm, A.; Tramontano, A.; Luzzago, A.; Nicosia, A. J. Mol. Biol., 2000, 296, 497.

[11] Crameri, R.; Suter, M. Gene, 1993, 137, 69.

[12] Crameri, R.; Hemmann, S.; Blaser, K. Adv. Exp. Med. Biol., 1996, 409, 103.

[13] Jespers, L.S.; Messens, J.H.; De Keyser, A.; Eeckhout, D.; Van den Brande, I.; Gansemans, Y.G.; Lauwereys, M.J.; Vlasuk, G.P.; Stanssens, P.E. Biotechnology (NY), 1995, 13, 378.

[14] Maenaka, K.; Furuta, M.; Tsumoto, K.; Watanabe, K.; Ueda, Y.; Kumagai, I. Biochem. Biophys. Res. Commum., 1996, 218, 682 .

[15] Hufton, S.E.; Moerkerk, P.T.; Meulemans, E.V.; de Bruine, A.; Arends, J.W.; Hoogenboom, H.R. J. Immunol. Methods, 1999, 231, 39.
[16] Rhyner, C.; Kodzius, R.; Crameri, R. Curr. Pharm. Biotechnol., 2002, 3,13 .

[17] Castagnoli, L.; Zucconi, A.; Quondam, M.; Rossi, M.; Vaccaro, P.; Panni, S.; Paoluzi, S.; Santonico, E.; Dente, L.; Cesareni, G. Comb. Chem. High Throughput Screen., 2001, 4, 121.

[18] Rhyner, C.; Weichel, M.; Flückiger, S.; Hemmann, S.; KleberJanke, T.; Crameri, R. Methods, 2004, 32, 212.

[19] Fossa. A.; Alsoe, L.; Crameri, R.; Funderud, S.; Gaudernack, G.; Smeland, E.B. Cancer Immunol. Immunother., 2004, 53, 431.

[20] Kemp, E.H.; Herd, L.M.; Waterman, E.A.; Wilson, A.G.; Weetman, A.P.; Watson, P.P. Biochem. Biophys. Res. Commun., 2002 $298,169$.

[21] Palzkill, T.; Huang, W.; Weinstock, G.M. Gene, 1998, 221, 79.

[22] Fransen, M.; Van Veldhoven, P.P.; Subramani, S. Biochem. J., 1999, 340, 561.

[23] McCafferty, J.; Jackson, R.H.; Chiswell, D.J. Protein Eng., 1991 , 4,955 .

[24] Chaidaroglou, A.; Brezinski, D.J.; Middleton, S.A.; Kantrowitz, E.R. Biochemistrty, 1988, 27, 8338 .

[25] Müller-Hartmann, H.; Müller-Hill, B. J. Mol. Biol., 1996, 257, 473.

[26] Levitan, B. J. Mol. Biol., 1998, 277, 916.

[27] Geisberger, R.; Prlic, M.; Achatz-Straussberger, G.; Oberndorfer, I.; Luger, E.; Lamers, M.; Crameri, R.; Appenzeller, U.; Wienands, J.; Breitenbach, M.; Ferreira, F.; Achatz, G. Dev. Immunol., 2002, 9, 127.

[28] Bradshaw, R.A.; Cancedda, F.; Ericsson, L.H.; Neumann, P.A.; Piccoli, S.P.; Schlesinger, M.J.; Shriefer, K.; Walsh, K.A. Proc. Natl. Acad. Sci. USA, 1981, 78, 3473.

[29] Boulanger, R.R. Jr.; Kantrowitz, E.R. J. Biol. Chem., 2003, 278 , 23497.

[30] McCracken, S.; Meighen, E. J. Biol. Chem., 1980, 255, 2396.

[31] Gailus, V.; Rasched, I. Eur. J. Biochem., 1994, 222, 927.

[32] Il'ichev, A.A.; Minenkova, O.O.; Tat'kov, S.I.; Karpyshev, N.N.; Eroshkin, A.M.; Petrenko, V.A.; Sandakhchiev, L.S. Dokl. Akad. Nauk. SSSR, 1989, 307, 481

[33] Greenwood, J.; Willis, A.E.; Perham, R.N. J. Mol. Biol., 1991, 220 , 821.

[34] Iannolo, G.; Minenkova, O.; Petruzzelli, R.; Cesareni, G. J. Mol. Biol., 1995, 248, 835 .

[35] Malik, P.; Terry, T.D.; Gowda, L.R.; Langara, A.; Petukhov, S.A.; Symmons, M.F.; Welsh, L.C.; Marvin, D.A.; Perham, R.N. J. Mol. Biol., 1996, 260, 9 .

[36] Kretzschmar, T.; Geiser, M. Gene, 1995, 115, 61.

[37] Crameri, R.; Suter, M. Gene, 1995, 160, 139.

[38] Dower, W.J.; Miller, J.F.; Ragsdale, C.W. Nucleic Acids Res., 1988, $16,6127$.

[39] Neu, H.C.; Heppel, L.A. J. Biol. Chem., 1965, 240, 3685.

[40] Halford, S.E. Biochem. J., 1971, 125, 319.

[41] Malamy, M.H.; Horecker, B.L. Biochemistry, 1964, 19, 1893. 